\title{
PENINGKATAN KEDISIPLINAN DENGAN KONSELING KELOMPOK MELALUI TEKNIK TOKEN ECONOMY BAGI PESERTA DIDIK SMPN 3 BANYUATES
}

\author{
TITIE FITRIAH NURHAYATI \\ UPTD SMPN 3 BANYUATES \\ titiefn84@gmail.com
}

\begin{abstract}
Discipline attitude is an important and main aspect of education, so it is hoped that students can control their behavior in accordance with applicable norms. In connection with this mission, it is felt the need for effective and efficient guidance and counseling services to help overcome the problems that are being faced by students. The guidance and counseling teachers considered the use of information services to be less than optimal, so this time using group counseling services. The purpose of this research is to improve the disciplinary behavior of students. There are many treatments that can be done to improve discipline, one of which is behavior modification therapy. What will be used in behavior modification is to use the token economy technique, namely by providing positive reinforcement. This guidance and counseling action research uses classroom action research. Purposive sampling technique was used in this guidance and counseling action research. Based on the results of observations made during the study, there was a significant change in disciplinary behavior from the act of giving the token economy in cycle 1 and cycle 2 .
\end{abstract}

\begin{abstract}
ABSTRAK
Sikap disiplin merupakan aspek penting dan utama dalam pendidikan, sehingga diharapkan peserta didik dapat mengontrol perilakunya sesuai dengan norma yang berlaku. Sehubungan dengan misi tersebut maka dirasakan perlu adanya layanan bimbingan dan konseling yang efektif dan efisien untuk membantu mengatasi permasalahan yang sedang dihadapi mahasiswa. Para guru bimbingan dan konseling menilai penggunaan layanan informasi kurang optimal, sehingga saat ini menggunakan layanan konseling kelompok. Tujuan dari penelitian ini adalah untuk meningkatkan perilaku disiplin siswa. Banyak pengobatan yang dapat dilakukan untuk meningkatkan kedisiplinan, salah satunya dengan terapi modifikasi perilaku. Yang akan digunakan dalam modifikasi perilaku adalah dengan menggunakan teknik ekonomi token yaitu dengan memberikan penguatan positif. Penelitian tindakan bimbingan dan konseling ini menggunakan penelitian tindakan kelas. Teknik purposive sampling digunakan dalam penelitian tindakan bimbingan dan konseling ini. Berdasarkan hasil observasi yang dilakukan selama penelitian, terdapat perubahan perilaku disiplin yang signifikan dari pemberian token economy pada siklus 1 dan siklus 2 .
\end{abstract}

Cara mengutip: Nurhayati, T.F. (2020). Peningkatan Kedisiplinan dengan Konseling Kelompok Melalui Teknik Token Economy Bagi Peserta Didik SMPN 3 Banyuates. Nusantara of Research : Jurnal Hasil-Hasil Penelitian Universitas Nusantara PGRI Kediri (e-Journal), 7(1), 60-66. https://doi.org/10.29407/nor.v7i1.15067

\section{PENDAHULUAN}

Dunia pendidikan semakin dihadapkan pada fenomena munculnya berbagai tantangan dan permasalahan. Permasalahan yang timbul diantaranya adalah dari beragam keaktifan siswa yang dirasa negatif. Menurut Masa remaja sangat potensial untuk berkembang 
ke arah positif ataupun negatif. Dalam masa peralihan tersebut, remaja banyak mengalami perubahan-perubahan, diantaranya adalah perubahan fisik, psikologis, dan sosial. Ketidakmampuan remaja dalam menghadapi perubahan dalam dirinyalah yang menyebabkan munculnya kenakalan ataupun perilaku menyimpang lainnya (Diananda Amita, 2018).

Terdapat beberapa faktor pemicu terjadinya kenakalan remaja. Pertama, faktor internal, diantaranya adalah krisis identitas diri dan lemahnya kontrol diri. Kedua, faktor eksternal dapat berasal dari keluarga, masyarakat, bahkan sekolah (Bitar, 2020).

Sekolah tidak pernah lepas dari peraturan yang harus dipatuhi oleh seluruh anggota yang berada di dalamnya. Seringnya tidak patuh atau ketidakdisiplinan oleh para peserta didik ketika berada di wilayah sekolah diantaranya adalah keluar dari lingkungan sekolah tidak meminta izin guru atau pihak keamanan sekolah pada saat kegiatan belajar mengajar berlangsung, tidak menggunakan atribut sekolah sesuai dengan aturan tata tertib yang berlaku. Dalam hal ini banyak terjadi kasus-kasus kenakalan remaja di sekolah berhubungan dengan kedisiplinan.

Menurut Hurlock, disiplin adalah suatu cara sebuah lingkungan mengajarkan perilaku sehingga dapat diterima dapat diterima sesua budaya dalam lingungan tersebut. Curwin \& Mendler (2018) berpendapat bahwa disiplin merupakan sebuah proses tata cara dalam berinteraksi seseorang sehingga mampu dalam menentukan pilihan yang bertanggung jawab dan memecahkan masalah.

Sikap disiplin adalah aspek penting dan utama dalam pendidikan, sehingga diharapkan para peserta didik dapat mengendalikan tingkah lakunya dengan baik dan sesuai dengan adat atau norma yang ada. Berkaitan dengan misi tersebut, dirasakan perlu layanan bimbingan dan konseling yang benar-benar membantu siswa untuk memecahkan problem yang dihadapi oleh mereka.

Pengarahan dan pembiasaan yang diterapkan kepada peserta didik untuk dapat menjadi individu yang memiliki kepedulian terhadap aturan-aturan yang berlaku di sekolah adalah salah satu tugas dari guru bimbingan dan konseling. Guru bimbingan dan konseling adalah orang dewasa yang berkompeten, bertanggung jawab serta memiliki empati yang tinggi.

Penelitian ini menggunakan teknik modifikasi perilaku. Teknik modifikasi perilaku adalah salah satunya dari banyak treatment yang dapat dilakukan untuk meningkatkan kedisiplinan. Terapi tingkah laku memiliki ciri-ciri (1) Tingkah laku yang tampak dan spesifik menjadi pemusatan perhatian perlakuan, (2) Penjelasan dan kecermatan tujuan dari pada treatment, (3) Perumusan prosedur mengenai treatment yang jelas (spesifik) dengan masalah, (4) Penjelasan terhadap hasil-hasil terapi secara objektif (Corey, 2013).

Garry, M. (1999) menyatakan bahwa pendekatan modifikasi perilaku tersebut adalah berdasarkan pada prinsip behavioristik dimana pemberian tindakan kepada individu ketika nampaknya suatu perilaku baru. Salah satu teknik yang dapat dilakukan untuk meningkatkan perilaku kedisiplinan adalah dengan menggunakan teknik token economy yaitu dengan memberikan penguatan positif (positive reinforcement).

Menurut Martin dan Pear (2015) teknik token economy adalah salah satu program dari teori behavioral dimana peserta didik dapat memiliki token economy untuk merubah perilaku yang diingikan dan dapat menukarkannya setelah perilaku yang diinginkan terpenuhi sebagai 
penguatan perilaku. Kegiatan konseling kelompok dengan menggunakan token economy untuk merubah perilaku tidak disiplin pada peserta didik agar dapat menjadi perilaku yang disiplin. Pemberian token economy dilakukan kepada lima orang peserta didik sebagai penguatan agar dapat menjadi pribadi yang berperilaku disiplin.

Purwanta (2015) memberikan penjelasan tentang tahapan-tahapan dalam pelaksanaan token economy, tahapan pertama adalah tahapan awal atau disebut tahap persiapan, tahapan kedua adalah tahapan inti atau disebut tahap pelaksanaan, dan tahapan ketiga/terakhir adalah tahap evaluasi. Pada fase awal (tahap persiapan), konselor menentukan jenis perilaku-perilaku yang ingin diubah, menentukan harga setiap perilaku yang akan pada akhirnya kan ditukarkan dengan hadiah. Pada tahap pelaksanaan, konselor membuat kesepakatan dengan para peserta didik dalam pelaksanaan perubahan perilaku disiplin sesuai dengan yang telah tertera pada kartu token economy. Pada tahap terakhir yaitu tahap evaluasi, konselor menilai dan mengamati berbagai macam keberhasilan dan kekurangan dalam pemberian teknik token economy juga memberikan hadiah yang ditukarkan dengan kartu token economy milik peserta didik.

Berdasarkan hasil laporan dari guru mata pelajaran juga wali kelas, dan hasil observasi yang telah dilakukan oleh peneliti sebelumnya, bahwasannya ditemukan sebagian besar peserta didik SMPN 3 Banyuates kurang memiliki kedisiplinan di sekolah. Teknik token economy akan diberikan kepada para peserta didik untuk meningkatkan perilaku disiplin.

\section{METODE}

Penelitian Tindakan kelas menurut Arikunto (2006), mengandung tiga (3) unsur yaitu penelitian, Tindakan, dan Kelas. Penelitian yang dilakukan ini diadaptasi dari PTK namun lebih spesifik pada bidang bimbingan dan konseling (PTBK). Menurut Kemmis dan McTaggart (dalam Suharsono, 2019) Penelitian tindakan merupakan salah satu strategi yang memanfaatkan tindakan nyata dan proses pengembangan kemampuan dalam mendeteksi dan memecahkan masalah. Penelitian tindakan pada hakikatnya berupa rangkaian kegiatan yang terdiri dari empat langkah, yaitu perencanaan, tindakan, pengamatan, dan refleksi. Keempat langkah tersebut dipandang sebagai satu siklus penelitian tindakan. Dengan demikian pengertian siklus pada penelitian tindakan adalah satu putaran kegiatan yang terdiri dari perencanaan, tindakan, pengamatan, dan refleksi.Rancangan tindakan kelas untuk bimbingan dan konseling adalah rancangan dalam penelitian ini. Cara menentukan sample dalam penelitian yang digunakan peneliti adalah purposive sampling. Purposive sampling dalam penelitian ini merupakan perilaku kedisiplinan yang rendah pada peserta didik kelas IX di SMPN 3 Banyuates Sampang.

Beberapa tahapan-tahapan pelaksanaan dalam penelitian adalah: 1) Tahap persiapan yang berupa pembuatan RPL konseling kelompok dan kartu token economy, pedoman observasi yang berupa pengamatan-pengamatan tentang perilaku disiplin; 2)Tahap pelaksanaan merupakan kegiatan layanan konsleing kelompok dan pemberian treatment token economy; 3) Tahap pengamatan dimana peneliti melakukan observasi kepada peserta didik juga memberikan stiker pada kartu token economy jikan aktivitas dalam kartu dapat terpenuhi (dilaksanakan); 4) Tahap evaluasi adalah untuk melihan dan menilai perubahan-perubahan perilaku disiplin pada peserta didik juga penukaran kartu token economy dengan hadiah yang telah disepakati bersama. 
HASIL

Hasil pada siklus 1

Tabel 1. Hasil observasi berdasarkan frekuensi hari pertama

\begin{tabular}{clccccc}
\hline NO & \multicolumn{1}{c}{ Perilaku yang diamati } & Anis & Aminah & Dilla & Indah & Mia \\
\hline 1 & Datang tepat waktu ke sekolah & $\sqrt{ }$ & $\sqrt{ }$ & $\sqrt{ }$ & $\sqrt{ }$ & $\sqrt{ }$ \\
2 & Masuk tepat waktu ke dalam kelas & $\sqrt{ }$ & - & - & $\sqrt{ }$ & $\sqrt{ }$ \\
3 & $\begin{array}{l}\text { Kembali ke kelas setelah istirahat tepat } \\
\text { waktu }\end{array}$ & - & $\sqrt{ }$ & $\sqrt{ }$ & - & $\sqrt{ }$ \\
4 & $\begin{array}{l}\text { Menyelesaiakan seluruh tugas yang } \\
\text { diberikan }\end{array}$ & $\sqrt{ }$ & & $\sqrt{ }$ & - & - \\
5 & Mengumpulkan tugas tepat waktu & - & $\sqrt{ }$ & & $\sqrt{ }$ & - \\
\hline
\end{tabular}

Tabel 2. Hasil observasi berdasarkan frekuensi hari kedua

\begin{tabular}{clccccc} 
NO & \multicolumn{1}{c}{ Perilaku yang diamati } & Anis & Aminah & Dilla & Indah & Mia \\
\hline 1 & Datang tepat waktu ke sekolah & $\sqrt{ }$ & - & $\sqrt{ }$ & $\sqrt{ }$ & $\sqrt{ }$ \\
2 & Masuk tepat waktu ke dalam kelas & $\sqrt{ }$ & $\sqrt{ }$ & $\sqrt{ }$ & $\sqrt{ }$ & $\sqrt{ }$ \\
3 & $\begin{array}{l}\text { Kembali ke kelas setelah istirahat tepat } \\
\text { waktu }\end{array}$ & $\sqrt{ }$ & $\sqrt{ }$ & - & $\sqrt{ }$ & $\sqrt{ }$ \\
4 & $\begin{array}{l}\text { Menyelesaiakan seluruh tugas yang } \\
\text { diberikan }\end{array}$ & - & $\sqrt{ }$ & $\sqrt{ }$ & $\sqrt{ }$ & $\sqrt{ }$ \\
5 & Mengumpulkan tugas tepat waktu & $\sqrt{ }$ & $\sqrt{ }$ & $\sqrt{ }$ & $\sqrt{ }$ & $\sqrt{ }$ \\
\hline
\end{tabular}

Tabel 3. Hasil observasi berdasarkan frekuensi hari ketiga

\begin{tabular}{clccccc}
\hline \multirow{2}{*}{ NO } & \multicolumn{1}{c}{ Perilaku yang diamati } & Anis & Aminah & Dilla & Indah & \multicolumn{2}{c}{ Mia } \\
\hline 1 & Datang tepat waktu ke sekolah & $\sqrt{ }$ & $\sqrt{ }$ & $\sqrt{ }$ & $\sqrt{ }$ & $\sqrt{ }$ \\
2 & Masuk tepat waktu ke dalam kelas & $\sqrt{ }$ & $\sqrt{ }$ & $\sqrt{ }$ & $\sqrt{ }$ & $\sqrt{ }$ \\
3 & $\begin{array}{l}\text { Kembali ke kelas setelah istirahat tepat } \\
\text { waktu }\end{array}$ & $\sqrt{ }$ & $\sqrt{ }$ & $\sqrt{ }$ & $\sqrt{ }$ & $\sqrt{ }$ \\
4 & $\begin{array}{l}\text { Menyelesaiakan seluruh tugas yang } \\
\text { diberikan }\end{array}$ & - & $\sqrt{ }$ & - & - & $\sqrt{ }$ \\
5 & Mengumpulkan tugas tepat waktu & $\sqrt{ }$ & $\sqrt{ }$ & $\sqrt{ }$ & $\sqrt{ }$ & $\sqrt{ }$ \\
\hline
\end{tabular}

\section{Hasil pada siklus 2}

Tabel 4. Hasil observasi berdasarkan frekuensi hari pertama

\begin{tabular}{clccccc}
\hline NO & \multicolumn{1}{c}{ Perilaku yang diamati } & Anis & Aminah & Dilla & Indah & Mia \\
\hline 1 & Datang tepat waktu ke sekolah & $\sqrt{ }$ & $\sqrt{ }$ & $\sqrt{ }$ & $\sqrt{ }$ & $\sqrt{ }$ \\
2 & Masuk tepat waktu ke dalam kelas & $\sqrt{ }$ & $\sqrt{ }$ & $\sqrt{ }$ & $\sqrt{ }$ & $\sqrt{ }$ \\
3 & $\begin{array}{l}\text { Kembali ke kelas setelah istirahat tepat } \\
\text { waktu }\end{array}$ & $\sqrt{ }$ & $\sqrt{ }$ & $\sqrt{ }$ & $\sqrt{ }$ & $\sqrt{ }$ \\
4 & $\begin{array}{l}\text { Menyelesaiakan seluruh tugas yang } \\
\text { diberikan }\end{array}$ & $\sqrt{ }$ & $\sqrt{ }$ & $\sqrt{ }$ & $\sqrt{ }$ & $\sqrt{ }$ \\
5 & Mengumpulkan tugas tepat waktu & $\sqrt{ }$ & $\sqrt{ }$ & $\sqrt{ }$ & $\sqrt{ }$ & $\sqrt{ }$ \\
\end{tabular}


Nurhayati, T.F.

Peningkatan Kedisiplinan dengan Konseling Kelompok Melalui Teknik Token Economy Bagi Peserta Didik...

Tabel 5. Hasil observasi berdasarkan frekuensi hari kedua

\begin{tabular}{clccccc}
\hline NO & \multicolumn{1}{c}{ Perilaku yang diamati } & Anis & Aminah & Dilla & Indah & Mia \\
\hline 1 & Datang tepat waktu ke sekolah & $\sqrt{ }$ & $\sqrt{ }$ & $\sqrt{ }$ & $\sqrt{ }$ & $\sqrt{ }$ \\
2 & Masuk tepat waktu ke dalam kelas & $\sqrt{ }$ & $\sqrt{ }$ & $\sqrt{ }$ & $\sqrt{ }$ & $\sqrt{ }$ \\
3 & $\begin{array}{l}\text { Kembali ke kelas setelah istirahat tepat } \\
\text { waktu }\end{array}$ & $\sqrt{ }$ & $\sqrt{ }$ & $\sqrt{ }$ & $\sqrt{ }$ & $\sqrt{ }$ \\
4 & $\begin{array}{l}\text { Menyelesaiakan seluruh tugas yang } \\
\text { diberikan }\end{array}$ & $\sqrt{ }$ & $\sqrt{ }$ & $\sqrt{ }$ & $\sqrt{ }$ & $\sqrt{ }$ \\
5 & Mengumpulkan tugas tepat waktu & $\sqrt{ }$ & $\sqrt{ }$ & $\sqrt{ }$ & $\sqrt{ }$ & $\sqrt{ }$ \\
\hline
\end{tabular}

Tabel 6. Hasil observasi berdasarkan frekuensi hari ketiga

\begin{tabular}{clccccc}
\hline NO & \multicolumn{1}{c}{ Perilaku yang diamati } & Anis & Aminah & Dilla & Indah & Mia \\
\hline 1 & Datang tepat waktu ke sekolah & $\sqrt{ }$ & $\sqrt{ }$ & $\sqrt{ }$ & $\sqrt{ }$ & $\sqrt{ }$ \\
2 & Masuk tepat waktu ke dalam kelas & $\sqrt{ }$ & $\sqrt{ }$ & $\sqrt{ }$ & $\sqrt{ }$ & $\sqrt{ }$ \\
3 & $\begin{array}{l}\text { Kembali ke kelas setelah istirahat tepat } \\
\text { waktu }\end{array}$ & $\sqrt{ }$ & $\sqrt{ }$ & $\sqrt{ }$ & $\sqrt{ }$ & $\sqrt{ }$ \\
4 & $\begin{array}{l}\text { Menyelesaiakan seluruh tugas yang } \\
\text { diberikan }\end{array}$ & $\sqrt{ }$ & $\sqrt{ }$ & $\sqrt{ }$ & $\sqrt{ }$ & $\sqrt{ }$ \\
5 & Mengumpulkan tugas tepat waktu & $\sqrt{ }$ & $\sqrt{ }$ & $\sqrt{ }$ & $\sqrt{ }$ & $\sqrt{ }$ \\
\hline
\end{tabular}

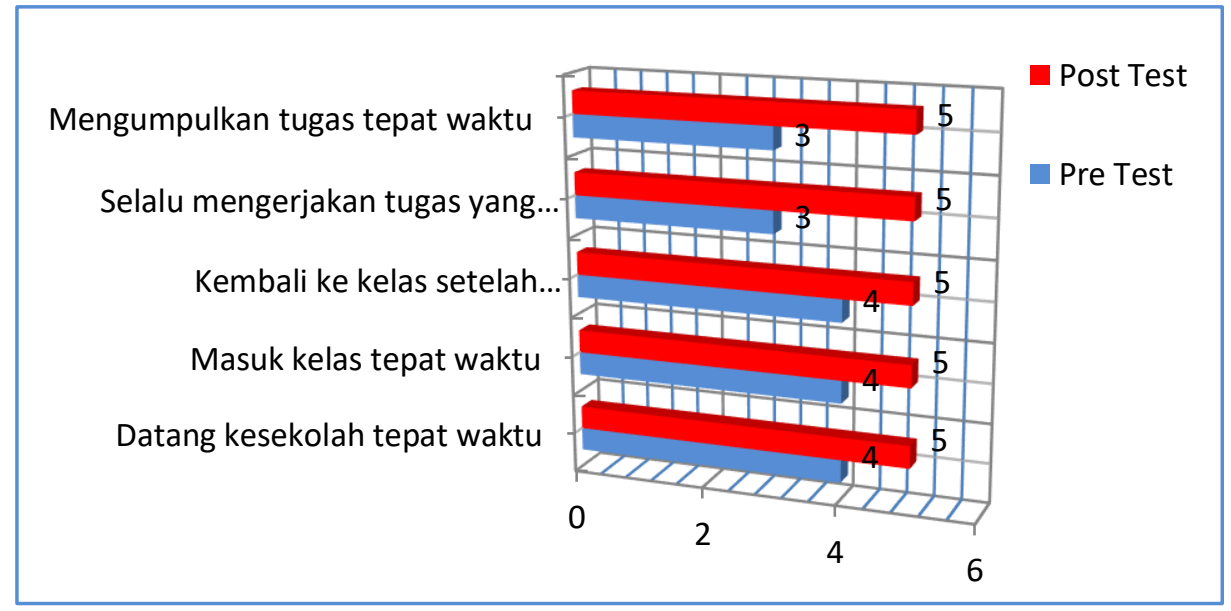

Grafik 1. Hasil perbandingan kartu token ekonomy pada hasil pre test dan post test

Berdasarkan grafik di atas tentang perbedaan hasil dari pretest dan post test yang telah dilaksanakan dapat terlihat jelas perubahan-perubahan perilaku disiplin yang terjadi pada para peserta didik kelas IX SMPN 3 Banyuates Sampang.

\section{PEMBAHASAN}

Pelaksanaan pada pretest tidak seluruh peserta didik mengalami peningkatan perubahan perilaku disiplin.Hal tersebut dikarenakan oleh beberapa faktor, yaitu belum 
terbiasanya dengan penggunaan jadwal yang telah dibuatnya untuk dapat mengatur kegiatannya sehari-hari. Kurang pemahaman peserta didik terhadap salah satu mata pelajaran sehingga tidak menuntaskan kegiatan yang ada pada kartu token economy juga membuatnya terlambat dalam pengumpulan tugas-tugas yang telah diberikan. Terakhir adalah kurang mampu untuk tidak mengikuti teman-temannya dalam melakukan pelanggaran-pelanggaran tata tertib di kelas maupun sekolah.

Pada pelaksanaan post test, peserta didik mendapatkan penguatan lagi terkait dengan tujuan penelitian yang ingin dilakukan oleh peneliti (Hikmah, 2016). Peneliti dan peserta didik melaksanakan konseling kelompok lagi dan membahas kendala-kendala yang telah dialami oleh peserta didik. Peneliti memberikan kartu token economy untuk kedua kalinya kepada peserta didik. Pada akhirnya seluruh peserta didik dapat menuntaskan keseluruhan kegiatan yang tertera pada kartu token economy (Corey, 2013).

Hasil pada post test, seluruh peserta didik dapat tuntas menyelesaikan kegiatankegiatan yang terdapat pada kartu token economy. Kegiatan-kegiatannya adalah: 1) Peserta mampu untuk datang ke sekolah dengan tepat waktu; 2) Peserta mampu untuk masuk ke kelasnya tepat waktu minimal sebelum dewan guru hadir (Mufidah Umri, 2013); 3) Peserta mampu untuk masuk kembali ke kelas dengan tepat waktu setelah waktu istirahat;4) Peserta mampu untuk mengumpulkan tugas-tugas yang telah terselesaikan pengerjaannya sesuai dengan tenggat waktu yang diberikan.

\section{KESIMPULAN DAN SARAN}

Berdasarkan hasil penelitian dapat disimpulkan bahwa ada peningkatan kedisiplinan dengan konseling kelompok melalui teknik token economy bagi peserta didik SMPN 3 Banyuates. Meski peningkatan sikap disiplin pada peserta didik dalam penelitian yang dilakukan ini tidak langsung tercapai pada siklus 1. Namun meningkat secara keseluruhan pada siklus 2.

Dari hasil penelitian yang telah dilakukan oleh peneliti, terdapat beberapa saran yang dapat digunakan sebagai bahan pertimbangan, yaitu: 1) Untuk dapat tercapainya tujuan-tujuan dalam layanan dalam pembelajaran, dan prestasi yang lebih baik, maka peserta didik perlu melanjutkan dan terus meningkatkan perilaku kedisiplinan yang telah terbentuk; 2) Guru BK sebaiknya membuat jadwal layanan konseling kelompok secara teratur pada setiap tingkatan kelas sehingga dapat mengentaskan permasalahan kedisiplinan peserta didik. 3) Diharapkan adanya kerjasama yang sangat baik dari orang tua (wali) peserta didik, agar memudahkan perubahan dalam perilaku yang akan diberikan tindakan sebagai bahan untuk penelitian selanjutnya.

\section{DAFTAR RUJUKAN}

Afid, Burhanuddin. 2013. https://afidburhanuddin.wordpress.com/2013/09/24/pengumpulandata-dan-instrumen-penelitian-6/. (diakses 18 September 2020).

Arikunto, S. 2006. Prosedur Penelitian: Suatu Pendekatan Praktek. Jakarta: PT. Rinekacipta

Bitar. 2020. Kenakalan remaja: Pengertian,Ciri, Contoh, Penyebab dan Solusinya. www.gurupendidikan.co.id. (diakses 18 September 2020)

Curwin, L.R., Mendler, N.A., \& Brian, D.M. (2018). Discipline with Dignity. USA: ASCD.

Corey, Gerald. 2013. Teori dan Praktek Konseling dan Psikoterapi. Bandung: Rafika Aditama. 
Diananda Amita. 2018. Psikologi remaja dan permasalahannya. https://www.researchgate.net/publication/331705902_PSIKOLOGI_REMAJA_DAN_P ERMASALAHANNYA (diakses 18 September 2020)

Garry, M. (1999). Behavior Modification: What It Is and How to Do It. (6th ed.) Upper Saddle River, New Jersey: Prentice-Hall.

Hikmah Nurul. 2016. Peran post test terhadap motivasi belajar siswa pada mata pelajaran sosiologi di SMA Negeri 11 Makassar. Jurusan PPKn FKIP UNM

Hurlock. 2000. "Psikologi Perkembangan". (Jakarta:PT.Gelora Aksara Pratama)

Martin. Garry\& Pear. Joseph. 2015. Modifikasi Perilaku: Makna dan Penerapannya. Yogyakarta: Pustaka Belajar.

Mufidah Umri. 2013. Efektivitas Pemberian Reward Melalui Metode Token Ekonomi Untuk Meningkatan Kedisiplinan Anak Usia Dini. Jurusan Pendidikan Guru Anak Usia Dini FKIP UNNES

Mughnifar Ilham. 2020. 25 Pengertian Observasi Menurut Para Ahli. https://www.materi.carageo.com/pengertian-observasi-menurut-para-ahli//(diakses 18 September 2020)

Purwanta, Edi. 2015. Modifikasi Perilaku. Yogyakarta: Pustaka Belajar.

Salamadian. 2017. https://salamadian.com/teknik-pengambilan-sampel-sampling/ (diakses 18 September 2020)

Suharsono. 2019. Pendalaman Materi Bimbingan Konseling. Kementerian Pendidikan dan Kebudayaan. 